\title{
REVISÃO DO GÊNERO PTERACANTHA (COLEOPTERA, CERAMBYCIDAE, CERAMBYCINAE, TRACHYDERINI)
}

\author{
Miguel A. Monné ${ }^{1}$ \\ Marcela L. Monné ${ }^{2}$
}

\begin{abstract}
REVISION OF THE GENUS PTERACANTHA (COLEOPTERA, CERAMBYCIDAE, CERAMBYCINAE, TRACHYDERINI). The genus Pteracantha Newman, 1838 is revised and P. agrestis sp. nov. is described from Brazil (Minas Gerais).
\end{abstract}

KEYWORDS. Cerambycidae, Trachyderini, Pteracantha, taxonomy, Neotropical.

\section{INTRODUÇÃO}

Esta contribuição objetiva prosseguir o estudo do grupo de gêneros considerados por ThOMson (1864) como "Tropidosomitae", dentro da tribo Trachyderini, tendo sido constatada a existência de espécie inédita pertencente ao gênero Pteracantha Newman, 1838. O material estudado pertence ao Museu Nacional, Universidade Federal do Rio de Janeiro (MNRJ).

\section{Pteracantha Newman, 1838}

Pteracantha Newman, 1838:392; Thomson, 1860:207; 1864:259, 458; LACORDAiRe, 1869:152. Amallocerus GuÉrin-MÉnevilLe, 1844:218; Thomson, 1860:209 (sin.).

Dorso da cabeça com pontos grossos, adensados na região posterior. Fronte curta, vertical e deprimida. Tubérculos anteníferos pouco projetados, próximos entre si e divididos por sulco longitudinal. Submento com pontos finos, rasos e esparsos. Genas subtriangulares, paralelas, com pontos finos e esparsos e comprimento subigual ao diâmetro do lobo ocular inferior; superfície com pontos finos, rasos e esparsos. Mandíbulas com depressão láterolongitudinal; $2 / 3$ basais com pontos densos e 1/3 apical liso. Artículos apicais dos palpos maxilares estreitados na base e no ápice e este truncado; com poro sensorial ovalado na metade apical. Antenas com onze antenômeros e marcado dimorfismo sexual. Sistema porífero dividido por carena longitudinal ao longo da margem lateral externa; nos machos, na metade apical do antenômero III e em toda margem lateral externa dos IV-XI; nas fêmeas,

1. Museu Nacional, Universidade Federal do Rio de Janeiro, Quinta da Boa Vista, 20940-040, Rio de Janeiro, RJ, Brasil. (Bolsista CNPq)

2. Curso de Pós-Graduação em Entomologia, Departamento de Zoologia, Universidade Federal do Paraná, Caixa Postal 19020, 81531-990, Curitiba, PR, Brasil. (Bolsista Doutorado CAPES) 
em toda margem lateral externa dos III-XI. Protórax mais largo que longo, a margem posterior mais larga que a anterior; aos lados com dois tubérculos, um próximo à margem anterior $\mathrm{e}$ o outro mediano, mais desenvolvido. Pronoto levemente convexo, com pontos grossos e foveolados; com carena longitudinal mediana lisa, que não alcança a margem posterior e dois tubérculos centro-medianos. Processo prosternal cerca de dois terços do diâmetro de uma procoxa, elevado e, anterior e posteriormente, em declive. Cavidades cotilóides anteriores abertas atrás. Processo mesosternal proeminente e projetado anteriormente em tubérculo rombo. Cavidades cotilóides médias fechadas aos lados. Mesepimero, mesepisterno e metepisterno micropontuados e com pubescência esparsa. Élitros glabros, com pelo menos quatro carenas longitudinais lisas; três carenas longas iniciadas na base e não alcançam os ápices elitrais e uma curta, próxima ao escutelo, que atinge o quarto anterior; superfície densamente pontuada, na metade apical pouco mais fina que na metade basal. Úmeros arredondados, não projetados. Extremidades elitrais arredondadas e com espinho proeminente na margem externa. Pernas curtas; superfície grosseiramente pontuada; as posteriores cerca de 1,5 vezes mais longas que as anteriores. Fêmures lineares, levemente deprimidos lateralmente. Meso- e metafêmures, na metade apical do dorso, com cerdas curtas e densas. Tíbias pouco mais curtas que os fêmures, cilíndricas e deprimidas. Tarsos curtos, primeiro metatarsômero mais curto que os dois seguintes reunidos; escovas tarsais compactas. Abdome com superfície brilhante, pontos finos e esparsos e pilosidade rala e amarela. Urosternito III cerca de 1,5 vezes mais longo que o seguinte.

Discussão. O gênero Pteracantha foi proposto por NewMAN (1838) para única espécie, P. fasciata proveniente de Brasil. GuÉRIN-MÉnEville (1844) descreveu Amallocerus para A. spinosus do Brasil. Thomson (1860) estabeleceu a sinonímia entre ambos os nomes genéricos e considerou P. spinosus como a combinação prioritária. LACORDAIRE (1869) redescreveu Pteracantha e acertadamente arrolou P. fasciata como o nome válido.

Pteracantha, Ctenodes Olivier, 1807 e Tropidosoma Perty, 1832 compõem um grupo de gêneros de Trachyderini, cujas semelhanças e diferenças foram discutidas em MoNNÉ \& MONNÉ (1998).

\section{Pteracantha fasciata Newman, 1838}

(Figs. 1-7)

Pteracantha fasciata Newman, 1838:393; White, 1853:81; LaCordaire, 1869:153; 1876:est. 94, fig. 1; ZaJCiw, 1958:15, 23 (distr.).

Amallocerus spinosus GuÉrin-Méneville, 1844:218; Aurivillius, 1912:451 (sin., cat.).

Pteracantha spinosa; Thomson, 1864:259; 1878:16 (type); Bruch, 1912:204 (cat.).

Cabeça totalmente preta ou com tubérculos anteníferos e região ventral amarelos; antenas, mesepimero, mesepisterno, metepisterno, pernas e abdome castanho-escuros a pretos; pronoto e lados do protórax pretos, exceto carena mediana e tubérculos, amarelos; prosterno amarelo ou com mancha mediana preta; mesosterno castanho a preto, exceto processo amarelo; metasterno castanho a preto, com faixa longitudinal mediana amarela; escutelo amarelo a preto; élitros (figs. 1-5) amarelos com terço apical pretos, a totalmente pretos com apenas duas manchas amarelas medianas. Região lateral dos lobos oculares, na margem posterior, com projeção aguçada. Antenas com aspecto aveludado e pubescência densa e preta. Escapo longo, robusto e engrossado para o ápice, na superfície dorsal com pontos finos e densos e na ventral com pontos grossos e esparsos; pedicelo curto e transverso. 

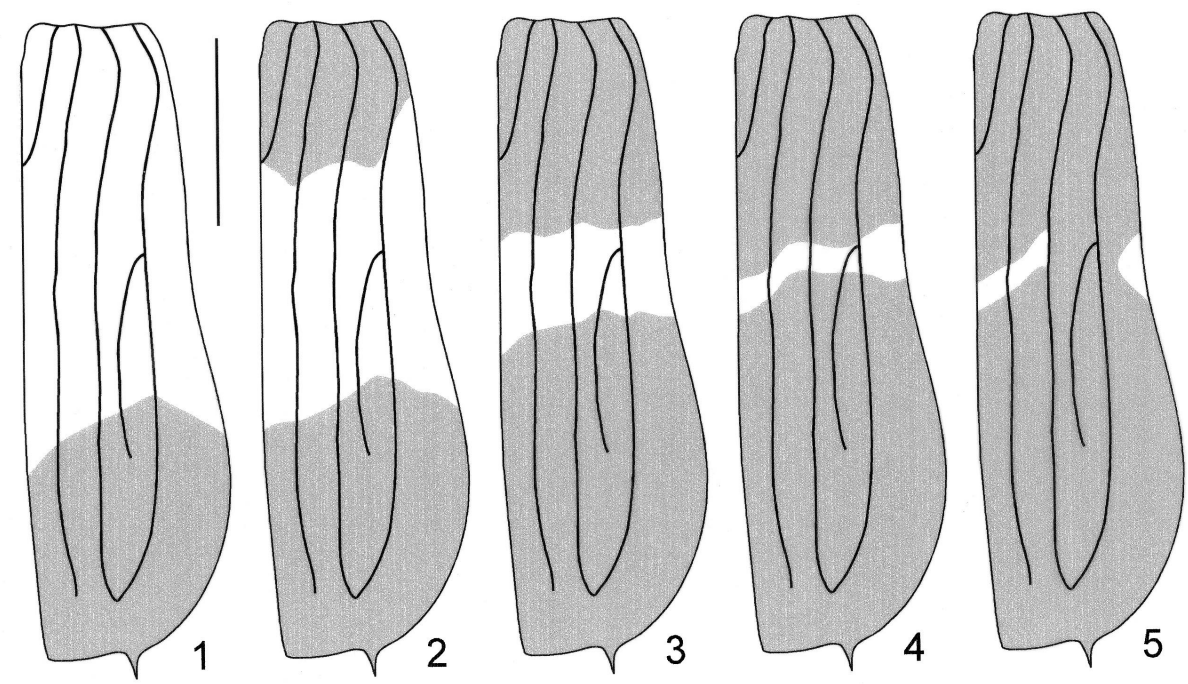

Figs. 1-5. Pteracantha fasciata Newman, 1838, variação no colorido dos élitros. Barra, 0,5 mm.

Antenas, nos machos (fig. 6), ultrapassam os ápices elitrais no antenômero VIII; III-V subserreados, VI-XI filiformes; escapo e IV subiguais e pouco menores que III ou V; V-VII gradualmente crescentes. VIII-X subiguais; XI cerca do dobro do X; nas fêmeas (fig. 7), serreadas, apenas alcançam o terço basal ou a metade dos élitros; escapo cerca do dobro do III; III-VI subiguais; VII-XI gradualmente decrescentes. Protórax com pêlos curtos, esparsos e castanho-escuros; nos lados com tubérculos acuminados. Pronoto (figs. 6, 7) com um tubérculo proeminente a cada lado da carena longitudinal mediana, próximo à margem posterior. Prosterno com pontos grossos, adensados aos lados. Mesosterno e metasterno com pêlos longos e amarelados e pontos finos e esparsos em toda superfície. Escutelo subtriangular, com pontos finos e esparsos, adensados nos lados. Élitros cerca de quatro vezes o comprimento do protórax, aplanados, lados divergentes para o ápice e com cinco carenas (figs. 1-7). Mesofêmures e metafêmures inermes. Metafêmures apenas alcançam o terço apical dos élitros. Último urosternito com margem apical truncada nos machos e sinuosa nas fêmeas.

Dimensões em mm, respectivamente $\delta / q$. Comprimento total, 21,4-27,0/18,1-26,3; comprimento do protórax, 3,8-4,8/3,3-4,6; maior largura do protórax, 6,7-8,0/5,5-7,8; comprimento do élitro 15,3-20,0/13,3-20,0; largura umeral, 6,3-8,3/5,7-8,0.

Material examinado. BRASIL, Bahia: Encruzilhada (Motel da Divisa, Rodovia Rio-Bahia km 965, 960 m), ơ, 3 q, XII.1972, C. A. C. Seabra \& O. Roppa col.;, , X.1973, C. A. C. Seabra \& O. Roppa col.; Espírito Santo: Itapina,, , XII.1976, E. dos Santos col.; Linhares, \&, II.1964, A. Maller col.; उ, XII.1965, A. Maller col.; $\uparrow$, I.1966, A. Maller col.; ठ , I.1970, A. Maller col.; Rio de Janeiro: Rio de Janeiro (Corcovado),, , 10.XI.1952, D. Zajciw col.; Niteroi (Cavalão), ơ, X.1947, R. Arlé col.; Seropédica, , , XI.1954. Todos no MNRJ.

Bruch (1912) listou P. fasciata para Argentina, Misiones, procedência a ser confirmada. 

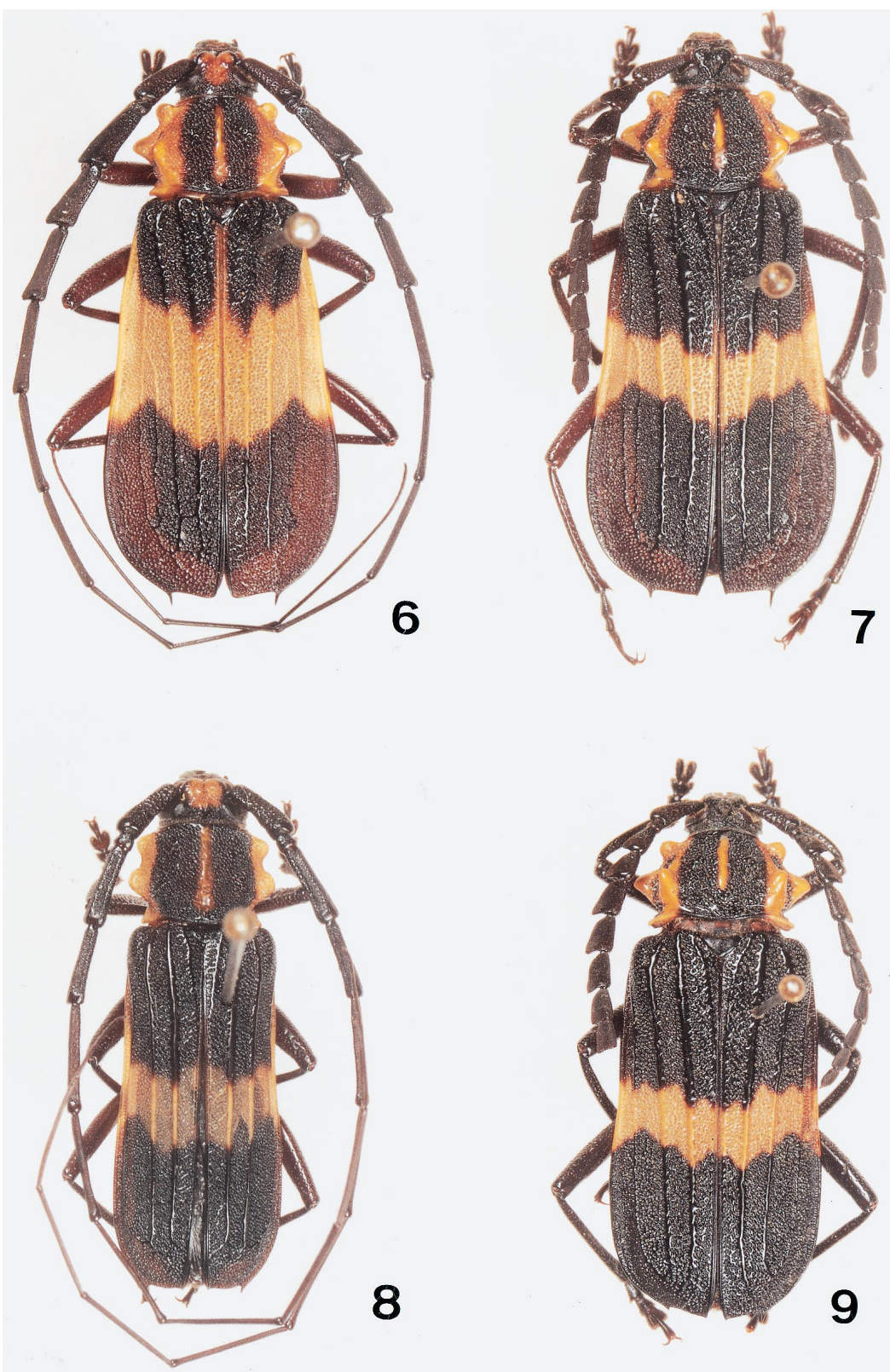

Figs. 6-9. Pteracantha fasciata Newman, 1838: 6, ơ, Brasil (Bahia, Encruzilhada), comprimento 24,5 $\mathrm{mm}$; 7,, , Brasil (Espírito Santo, Linhares), comprimento 25,7 mm. P. agrestis sp. nov.: 8, holótipo ơ', Brasil (Minas Gerais, Jaiba), comprimento 18,3 mm; 9, provável $\subsetneq$, Brasil (Piauí, Pimenteiras), comprimento $23,3 \mathrm{~mm}$. 


\section{Pteracantha agrestis sp. nov.}

(Fig. 8)

o. Cabeça amarela, exceto mandíbulas, genas e região dorsal, pretas; antenas, mesepimero, mesepisterno, metepisterno, escutelo, pernas e abdome castanho-escuros a pretos; protórax preto, exceto carena mediana longitudinal do pronoto, tubérculos laterais e faixa longitudinal mediana no prosterno, amarelos; mesosterno castanho-escuro, exceto processo mesosternal amarelo; metasterno castanho-escuro, exceto duas manchas medianas, uma próxima à margem anterior e outra na margem posterior, amarelas; élitros pretos com faixa transversal mediana amarela. Região lateral dos lobos oculares, na margem posterior, inerme. Antenas (fig. 8) filiformes, brilhantes e ultrapassam os ápices elitrais no antenômero VII; escapo cilíndrico, alongado, sulcado e com pontos grossos e densos; III-IV mais engrossados que os demais, sulcados e superfície com pontos densos e irregulares; V-XI micropontuados e com pubescência pouco aparente, preta. Escapo e antenômero IV subiguais em comprimento e pouco mais curtos que o III; V-X com comprimentos subiguais, XI cerca do dobro do X. Lados do protórax com tubérculos rombos. Pronoto (fig. 8) glabro, com um tubérculo obtuso, pouco evidente, próximo à margem posterior, a cada lado da carena longitudinal mediana. Prosterno com pontos grossos e densos e interstícios com pontos finos e pouco aparentes e pêlos curtos, esparsos e amarelados. Mesosterno com pontos finos e densos e pêlos densos, curtos, eretos e amarelados. Processo mesosternal cerca de dois terços do diâmetro de uma mesocoxa. Metasterno com pontos finos e esparsos, adensados aos lados e pêlos esparsos e amarelados. Escutelo subtriangular, com pontos finos e rasos. Élitros (fig. 8) cerca de três vezes o comprimento do protórax, com os lados paralelos até a declividade distal e com quatro carenas. Meso- e metafêmures com projeção apical interna curta e aguçada. Metafêmures alcançam o quarto apical dos élitros. Último urosternito com margem apical ligeiramente sinuosa.

Dimensões em mm, 3. Comprimento total, 18,3; comprimento do protórax, 3,5; maior largura do protórax, 5,0; comprimento do élitro, 12,5; largura umeral, 5,0.

Material-tipo. BRASIL, Minas Gerais: Jaiba (Mocambinho), holótipo J, XII.1997, C. E. de A. Julio col. (MNRJ).

Discussão. Pteracantha agrestis (fig. 8) difere de P. fasciata principalmente pelos antenômeros III-IV filiformes, pelo pronoto com tubérculos próximos à margem posterior, pouco aparentes e pretos e pelos élitros com os lados paralelos. Em P. fasciata (figs. 6, 7), os antenômeros III-IV são subserrreados, os tubérculos na margem posterior do pronoto são desenvolvidos e de coloração amarela e os lados dos élitros são divergentes para a extremidade.

Examinamos exemplar (fig. 9) proveniente de Pimenteiras, Piauí, Brasil, coletado por A. Aguirre em V.1973 e que possivelmente seja a fêmea de P. agrestis, contudo pela exiguidade de material e pela procedência diversa preferimos não considerá-la parátipo.

Agradecimentos. Ao Albino M. Sakakibara (Universidade Federal do Paraná) pelas fotografias e Paulo Roberto Valle da Silva Pereira pela arte final dos desenhos.

\section{REFERÊNCIAS BIBLIOGRÁFICAS}

Aurivillius, C. 1912. Coleopterorum Catalogus, pars 39, Cerambycidae: Cerambycinae. Berlin, W. Junk. $574 \mathrm{p}$. 
BRuch, C. 1912. Catálogo sistemático de los Coleópteros de la República Argentina.VIII. Família Cerambycidae. Revta Mus. La Plata, La Plata, 18:179-226.

GuÉRIN-MÉnevilLE, F. E. 1844. Iconographie du règne animal de G. Cuvier, ou réprésentation d'après nature de l'une des espèces les plus remarquables et souvent non figurées de chaque genre d'animaux. Insectes. Paris, Baillière. v. 7, 76 p.

Lacordaire, J. T. 1869. Histoire Naturelle des Insectes. Genera des Coléoptères. Paris, Roret. v. 9, n.1, $409 \mathrm{p}$.

1876. Histoire Naturelle des Insectes. Genera des Coléoptères. Atlas. Paris, Roret. 47 p., 134 est.

Monné, M. L. \& Monné, M. A. 1998. Sinopse do gênero Tropidosoma Perty, 1832 e novas sinonímias em Trachyderini (Coleoptera, Cerambycidae, Cerambycinae). Revta bras. Ent., São Paulo, 41(2-4):531-534.

Newman, E. 1838. Entomological notes. Ent. Mag., London, 5:168-182; 372-402; 483-500.

Thомson, J. 1860. Essai d'une classification de la famille des cérambycides et matériaux pour servir a une monographie de cette famille. Paris, Société Entomologique de France. 404 p.

1864. Systema cerambycidarum ou exposé de tous les genres compris dans la famille des cérambycides et familles limitrophes. Mém. Soc. r. Sci. Liège, Liège, 19:1-540. . 1878. Typi cerambycidarum Musei Thomsoniani. Paris, E. Deyrolle. 21 p.

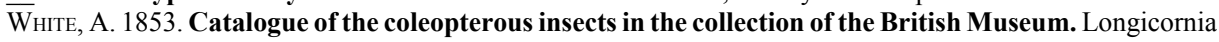
1. London, British Museum. v. 7, 174 p.

ZaJCIw, D. 1958. Fauna do Distrito Federal XLVIII. Contribuição para o estudo dos longicórneos do Rio de Janeiro (Coleoptera, Cerambycidae). Bolm Mus. nac., Rio de J., Nova Série, Zool., (189):1-26.

Recebido em 19.06.2001; aceito em 28.08.2001 